\title{
Setting for compact roundabout optimal lighting plans
}

\author{
A. Pratelli \\ Dipartimento di Ingegneria Civile "Vie e Trasporti", Univ. of Pisa, Italy
}

\begin{abstract}
This paper describes a method for choosing the optimal lighting plan related to roundabout dimensions. The method has been set up taking into account various illumination requirements and recommended standards, lighting apparel features and roundabout geometric characteristics. Moreover, the comparison between the central island solution and the perimetric location is completed by the inclusion of an estimation of the specific costs and related savings. All experimental findings are summarized into diagrams and tables allowing the designer to make the most proper lighting plan for a given design value of the inscribed diameter $D$, or vice versa. Our results are extended to values of $D$ ranging from 20 to $38 \mathrm{~m}$ and therefore the whole range of compact roundabouts is covered. These experimental results seem to confirm that the central solution is the best lighting practice for any compact roundabout.
\end{abstract}

Keywords: compact roundabouts, roundabout illumination requirements, best lighting practice.

\section{Introduction}

An unlit roundabout with one or more illuminated approaches is dangerous, because drivers approaching on an unlit branch will be attracted to the illuminated areas and may not see the intersection. A roundabout operates safely when drivers are able to perceive the general layout and operation of the roundabout in time to make their adequate manoeuvres, both during day and night. Therefore, one must provide an appropriate lighting of all roundabouts.

It is well known that modern roundabouts are classified by the dimensions of their inscribed circle diameter, $D$, as follows: a) mini-roundabouts, when $D$ is less than 20 metres; b) compact roundabouts, for $D$ of 20 to 38 metres; c) large, 
or rural, roundabouts, when $D$ is greater than 40 metres [1]. Mini-roundabouts are limited to applications for residential areas, while compact roundabouts are typical of urban contexts. Large roundabouts are more frequently built on suburban rings and rural highways.

National guides and guidelines contain general information on warranting conditions and design criteria, standard specifications for luminaire supports and mounting heights, as well as recommended illumination levels for different streets and areas $[2,3]$. There are several standard and recommended practices suggesting a central lighting plant for mini-roundabouts and a perimetrical, i.e. outside the external circumference, lighting scheme for large roundabouts [4].

However, no suggestion is given for compact roundabouts, i.e. roundabouts with inscribed diameter ranging from 20 to $38 \mathrm{~m}$, where the specific choice is left to the designer.

The following proposed design procedure has been set up taking into account various illumination requirements and recommended standards, lighting apparel features and roundabout geometric characteristics. Our method makes one able to compare the central lighting solution (Figure 1) and the perimetric location of luminaires (Figure 2) choosing for the optimal. Such a comparison is performed both by illumination requirements and by the inclusion of an estimation of specific costs and related savings and other benefits.

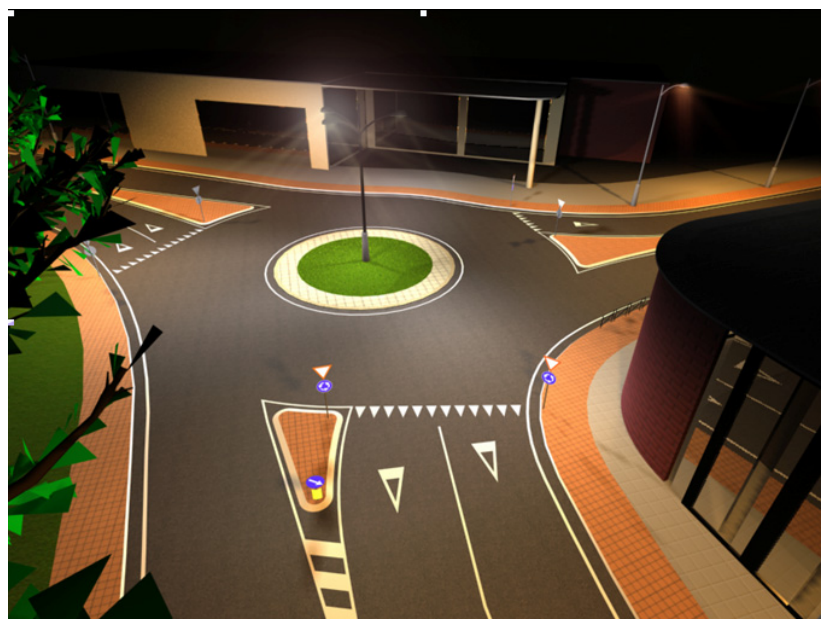

Figure 1: Central based lighting layout of a $30 \mathrm{~m}$ three arms compact roundabout powered by 250 watt lamps (3D simulation) [5].

\section{Design of lighting plans}

From a general point of view, the design process of lighting systems is usually based on the two principal criteria of average intensity and uniformity of illumination. Average intensity is a measure of the total illumination on the 


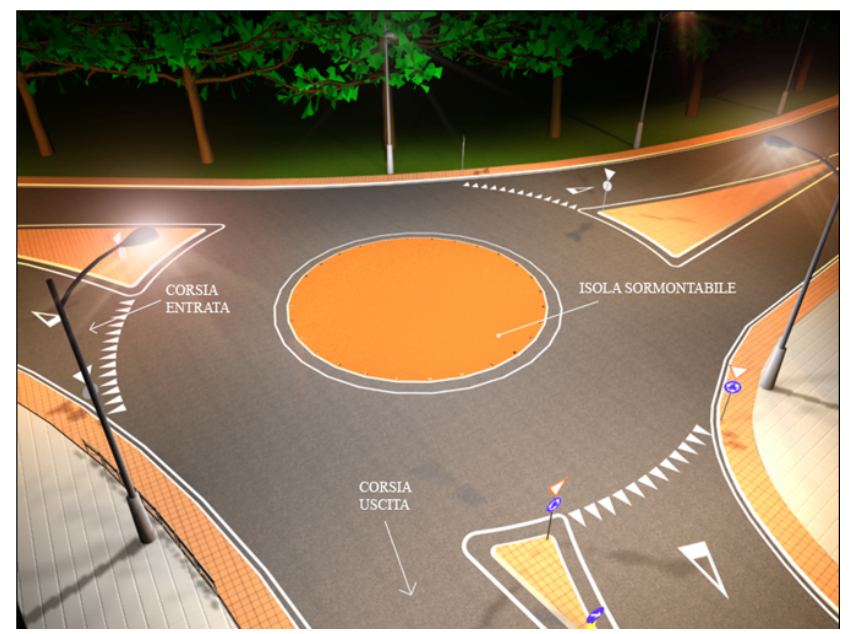

Figure 2: $\quad$ Perimetrical based lighting layout of a $25 \mathrm{~m}$ three arms compact roundabout powered by 250 watt lamps (3D simulation) [5].

roadway surface, and it is given in lumens per square meters on a horizontal surface. Uniformity of illumination, expressed in terms of minimum/average intensity ratio, describes how the total illumination is distributed on the roadway surface [6].

Average intensity of illumination is not necessarily directly related to the ability to see, which is essentially a function of the amount of light striking the roadway surface and diffused and reflected toward the driver's eye. Therefore seeing is directly related to pavement luminance, or brightness, characteristics.

Current guidelines give recommended values of average maintained horizontal illumination related to quite general conditions. These same guidelines indicate the prescribed minimum/maximum uniformity ratios on road pavement for different roads (e.g., local and residential streets should have a ratio not exceeding 1:6).

The lighting planning process primarily consists in evaluating the lighting needs, selecting appropriate illumination design criteria and proper light equipment, establishing the layout geometry in order to provide the most effective solution for the lighting needs. For instance, chapter 20 of the Transportation and Traffic Engineering Handbook [6] lists and resumes the main six steps involved in the design process of a lighting plan, starting from the analysis of the existing conditions and ending when a satisfactory check of the illumination uniformity is finally reached.

\section{Compact roundabout optimal lighting}

The ultimate task of illumination is to ensure perception of the roundabout and reciprocal visibility among the various vehicles at each entry. Adequate illumination levels are required at all conflict areas where traffic flows both 
entering to merge the circulating flow and exiting to leave the circulating flow. Ground-level lighting within the central island and splitter islands that shine upward towards the roadway improve the overall intersection visibility for approaching drivers.

General lighting requirements are reported in the CIE Guideline [2] where intersections are classified into five distinct categories. These are named from $\mathrm{C}_{1}$ to $\mathrm{C}_{5}$ and each one of them has a couple of specified values for the minimum average illumination, $E(\mathrm{~lx})$, and the overall uniformity ratio of luminance, Uo. This last one is expressed by the ratio $\left(L_{\min } / L_{a v}\right)$ where $L_{\min }$ and $L_{a v}$ are the minimum and the average levels of luminance, respectively, measured in $\left(\mathrm{cd} / \mathrm{m}^{2}\right)$. The quoted CIE Guideline assigns roundabouts to categories $\mathrm{C}_{1}$ or $\mathrm{C}_{2}$ or $\mathrm{C}_{3}$ in dependence both of geometrical complexity and location in urban or rural areas. Illumination quality of a roundabout lighting plan is often enhanced by additional standards. For instance, Swiss Guidelines [7] indicates that the average level of luminance assigned to the roundabout should be great $50 \%$ at least than the level measured on branches.

\subsection{Choosing a layout}

In respect to each given value of the inscribed diameter $D$ we have drawn the above correspondent illumination requirements from CIE Guideline [2]. Then, the first step was selecting among a set of feasible solutions the optimal one, both for the central and the perimetrical location of luminaries. This has been performed also taking into account the additional aspects listed below:

- costs of luminaries, lamps and poles;

- effectiveness of luminaries and light sources;

- $\quad$ average duration of lamps;

- $\quad$ installation plant and maintenance costs.

All these aspects lead to prefer layouts where there are the few number of light sources, the lesser required powers, the lower heights of poles. This first step has been performed by a trial-and-error approach assisted with a standard software package for any single computational evaluation of illumination and point-by-point spacing adjustments.

The second step was performed in comparison among the resulting layouts belonging to each one of the two different location schemes. We have made up some diagrams where experimental results are summarized for each instance of the examined roundabout geometries. The diagram of Figure 3, for instance, is related to the experimental results obtained for 25 metres inscribed diameter roundabouts. Whilst the diagram of Figure 4 is related to 30 metres roundabouts.

Given the roundabout dimension, $D$, though the proper diagram the designer can easily appreciate each alternative lighting plan when the main variables are changed in terms of:

- number of luminaries, or light sources;

- $\quad$ power rating of lamps (Watt);

- mounting heights on poles;

- $\quad$ type of lighting scheme (central or perimetrical). 
This way, one can compare the two alternative luminaire schemes, as much as analyze the same luminaire scheme under different choices of both the mounting heights and the power rating of lamps.

All the experimental diagrams are reported in [5]. For sake of saving space, here are reported only the diagrams for $25 \mathrm{~m}$ and $30 \mathrm{~m}$ roundabout instances as depicted in Figure 3 and Figure 4, respectively.

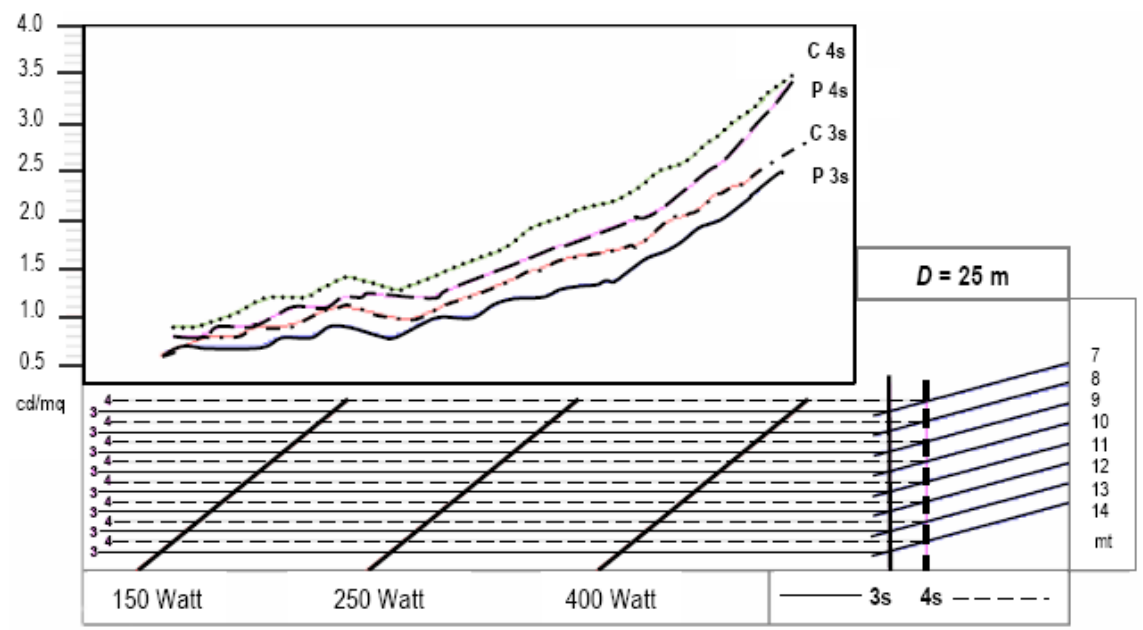

Figure 3: Diagram showing different alternative lighting layouts with respect of a $25 \mathrm{~m}$ inscribed diameter roundabout.

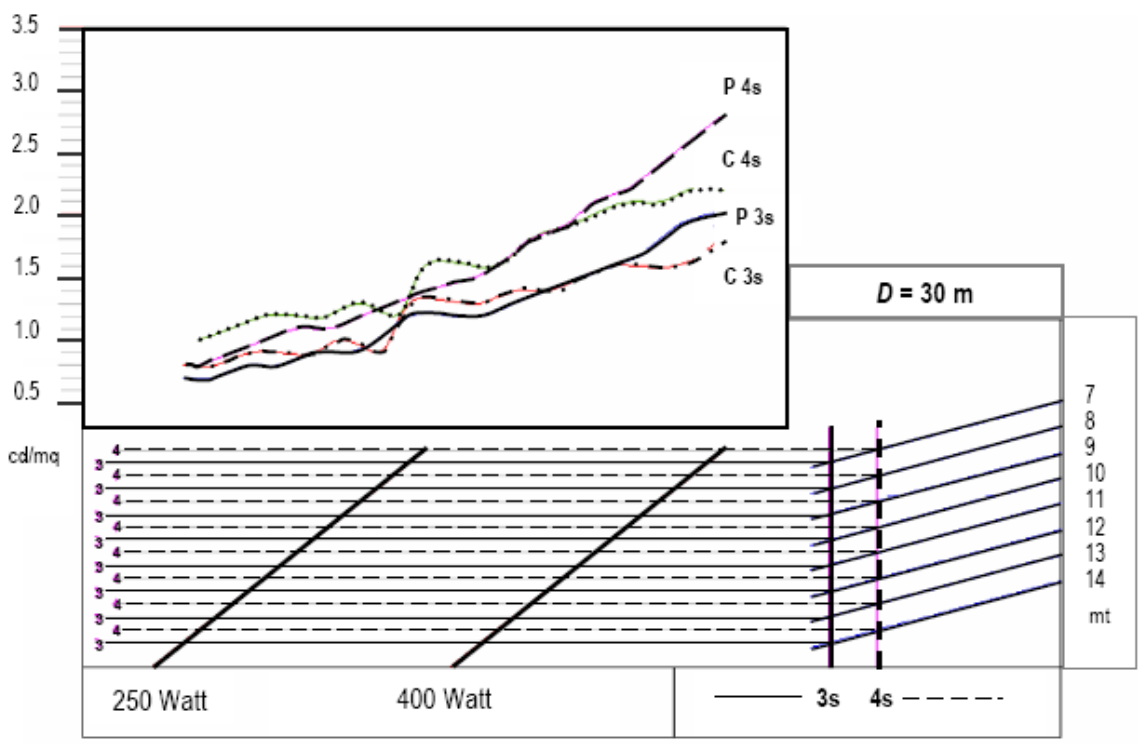

Figure 4: Diagram showing different alternative lighting layouts with respect of a $30 \mathrm{~m}$ inscribed diameter roundabout. 
As previously said, our computational procedures are referred to the intersection lighting values required by CIE Guideline [2]. The results showed in the diagrams are therefore related to those lighting solutions satisfying minimal requirements both of minimum luminance $L_{\text {min }}$ and of ratio of illumination $U o$. For instance, given a $25 \mathrm{~m}$ roundabout where the required value of minimum luminance is $L_{\min }=1,5 \mathrm{~cd} / \mathrm{m}^{2}$ and uniformity ratio $U_{o}=0,4$ one can use the diagram of Figure 3 in order to explore for 3 light sources alternatives. First, a horizontal line is drawn at the height of $1.5 \mathrm{~cd} / \mathrm{m}^{2}$; when such a line intercept the curve $C 3 s$, i.e. related to the central scheme, a vertical line is traced down till to the point crossing one of leaning lines related to light power (250 watt in the current example). From this cross point the horizontal line flagged with 3 (continuous) is followed on right since it crosses one of the mounting height lines related to $3 s$ (i.e. $8 \mathrm{~m}$ ). The same procedure can be followed for the perimetrical scheme, curve $P 3 s$, leading to a light power of 400 watt and mounting height of $13 \mathrm{~m}$ for each pole.

The lighting layout choice should also take into account if the roundabout is located in urban or rural areas. In the following we describe some experimental findings limiting our discussion to $25-30 \mathrm{~m}$ roundabouts.

\subsection{Cost analysis}

The aggregate cost of a given lighting system extended to its life cycle can be analytically expressed as:

$$
S=S_{0}+n S_{m}
$$

where $S_{0}$ is the construction cost, $n$ is the duration in years of the life cycle and $S_{m}$ is the maintenance cost per year.

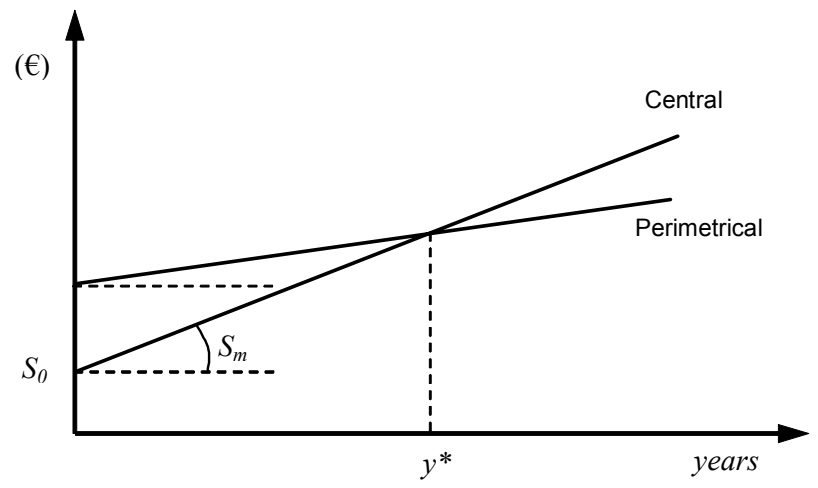

Figure 5: Linear cost model plotted for the two different layouts.

Components of the elementary costs both of $S_{0}$ and $S_{m}$ assume different sets of values in respect to the layout at hand. The construction cost takes into account 
needs for number of poles, luminarie supports and electrical connections. The maintenance costs are related to a service schedule based on expected lamp life and dirt accumulation characteristics of the area.

Moreover, the above cost model is a straight line where $S_{m}$ is its slope. Figure 5 shows the lines obtained for each of the two layout scheme with costs values drawn from current available statistics. These lines cross themselves at a point representing the cost indifference, or cost equilibrium. Speaking roughly, there is an amount of years, $y^{*}$, before which the central lighting layout is more economical than the perimetrical, while the vice versa holds after.

\subsection{Urban and rural locations}

The urban locations of $25-30 \mathrm{~m}$ roundabouts can be considered requiring minimal design values as much as the CIE Guideline [2] requires for miniroundabouts. It implies values of minimum luminance $L_{\min }=1,0-1,1 \mathrm{~cd} / \mathrm{m}^{2}$ and overall uniformity ratio of illumination $U_{o}=0,4$ with an average illumination $E$ of 15-20 lx (intersection category $\mathrm{C}_{2}$ or $\mathrm{C}_{3}$ ).

Table 1: Lighting plans obtained for the urban location of compact roundabouts from 25 to $30 \mathrm{~m}$ of the inscribed diameter assuming CIE minimum requirements [2].

\begin{tabular}{|c|c|c|c|c|c|c|c|}
\hline $\begin{array}{c}D \\
(\mathrm{~m})\end{array}$ & Layout & $\begin{array}{c}\text { Power } \\
(\text { Watt })\end{array}$ & $\begin{array}{c}\text { Light } \\
\text { sources }\end{array}$ & $\begin{array}{c}\text { Height } \\
(\mathrm{m})\end{array}$ & $U o$ & $\begin{array}{c}E \\
\left(\mathrm{~cd} / \mathrm{m}^{2}\right)\end{array}$ & $\begin{array}{c}L_{\min } \\
(\mathrm{lx})\end{array}$ \\
\hline 25 & $\mathrm{P}$ & 250 & 3 & 11 & 0.40 & 1.0 & 25 \\
\hline 25 & $\mathrm{P}$ & 150 & 4 & 10 & 0.40 & 1.0 & 23 \\
\hline 25 & $\mathrm{C}$ & 250 & 3 & 12 & 0.45 & 1.1 & 31 \\
\hline 25 & $\mathrm{C}$ & 150 & 4 & 11 & 0.45 & 1.1 & 29 \\
\hline 26 & $\mathrm{P}$ & 250 & 3 & 10 & 0.40 & 1.0 & 24 \\
\hline 26 & $\mathrm{P}$ & 150 & 4 & 9 & 0.40 & 1.0 & 23 \\
\hline 26 & $\mathrm{C}$ & 250 & 3 & 12 & 0.40 & 1.1 & 29 \\
\hline 26 & $\mathrm{C}$ & 150 & 4 & 11 & 0.40 & 1.0 & 28 \\
\hline 27 & $\mathrm{P}$ & 250 & 4 & 12 & 0.55 & 1.1 & 28 \\
\hline 27 & $\mathrm{C}$ & 250 & 3 & 12 & 0.40 & 1.0 & 27 \\
\hline 27 & $\mathrm{C}$ & 250 & 4 & 15 & 0.60 & 1.1 & 31 \\
\hline 28 & $\mathrm{P}$ & 250 & 4 & 11 & 0.45 & 1.1 & 27 \\
\hline 28 & $\mathrm{C}$ & 250 & 3 & 12 & 0.40 & 1.0 & 26 \\
\hline 28 & $\mathrm{C}$ & 400 & 3 & 18 & 0.60 & 1.1 & 33 \\
\hline 28 & $\mathrm{C}$ & 150 & 4 & 9 & 0.40 & 1.0 & 26 \\
\hline 28 & $\mathrm{C}$ & 250 & 4 & 14 & 0.55 & 1.1 & 31 \\
\hline 29 & $\mathrm{P}$ & 400 & 3 & 15 & 0.55 & 1.1 & 29 \\
\hline 29 & $\mathrm{P}$ & 250 & 4 & 10 & 0.45 & 1.1 & 27 \\
\hline 29 & $\mathrm{C}$ & 400 & 3 & 18 & 0.55 & 1.1 & 31 \\
\hline 29 & $\mathrm{C}$ & 250 & 4 & 13 & 0.50 & 1.1 & 31 \\
\hline 30 & $\mathrm{P}$ & 250 & 4 & 11 & 0.45 & 1.1 & 25 \\
\hline 30 & $\mathrm{C}$ & 400 & 3 & 17 & 0.55 & 1.1 & 31 \\
\hline 30 & $\mathrm{C}$ & 250 & 4 & 12 & 0.50 & 1.1 & 30 \\
\hline
\end{tabular}


Table 1 shows the set of lighting solutions obtained for urban instances using the minimum luminance $L_{\text {min }}=1,0-1,1 \mathrm{~cd} / \mathrm{m}^{2}$. We can observe that for $D=28 \mathrm{~m}$ there is a first central solution requiring lamps with 400 watt of power rating. These solutions are the optimal ones in respect to $D=29 \mathrm{~m}$ and $D=30 \mathrm{~m}$ roundabout instances. Roundabouts with $D=25 \mathrm{~m}$ or $D=26 \mathrm{~m}$ show quite similar lighting characteristics: the central layouts exceeds the perimetrical ones gaining 4-6 lx of average illumination and reaching 10\% plus of average luminance.

Moreover, central layouts are less costly because of the savings in number of poles and electrical conductors and, in correspondence of larger diameters, require less power amounts.

The same $25-30 \mathrm{~m}$ roundabouts should be considered of category $\mathrm{C}_{1}$ or $\mathrm{C}_{2}$ when located in rural areas. This leads to values of minimum luminance $L_{\min }=1,5-1,6 \mathrm{~cd} / \mathrm{m}^{2}$ and overall uniformity ratio of illumination $U o=0,4$ with an average illumination $E$ ranging from $20 \mathrm{~lx}$ and $30 \mathrm{~lx}$.

Table 2: Lighting plans obtained for the rural location of compact roundabouts from 25 to $30 \mathrm{~m}$ of the inscribed diameter assuming CIE minimum requirements [2].

\begin{tabular}{|c|c|c|c|c|c|c|c|}
\hline $\begin{array}{c}D \\
(\mathrm{~m})\end{array}$ & Layout & $\begin{array}{c}\text { Power } \\
(\text { Watt })\end{array}$ & $\begin{array}{c}\text { Light } \\
\text { sources }\end{array}$ & $\begin{array}{c}\text { Height } \\
(\mathrm{m})\end{array}$ & $U o$ & $\begin{array}{c}E \\
\left(\mathrm{~cd} / \mathrm{m}^{2}\right)\end{array}$ & $\begin{array}{c}L_{\min } \\
(\mathrm{lx})\end{array}$ \\
\hline 25 & $\mathrm{P}$ & 400 & 3 & 13 & 0.50 & 1.6 & 40 \\
\hline 25 & $\mathrm{P}$ & 250 & 4 & 10 & 0.40 & 1.5 & 34 \\
\hline 25 & $\mathrm{C}$ & 250 & 4 & 12 & 0.47 & 1.5 & 41 \\
\hline 26 & $\mathrm{P}$ & 400 & 3 & 13 & 0.50 & 1.5 & 38 \\
\hline 26 & $\mathrm{P}$ & 250 & 4 & 9 & 0.40 & 1.5 & 34 \\
\hline 26 & $\mathrm{C}$ & 250 & 4 & 11 & 0.40 & 1.5 & 42 \\
\hline 27 & $\mathrm{P}$ & 400 & 3 & 12 & 0.40 & 1.6 & 38 \\
\hline 27 & $\mathrm{C}$ & 400 & 4 & 15 & 0.45 & 1.5 & 42 \\
\hline 27 & $\mathrm{C}$ & 250 & 4 & 10 & 0.40 & 1.5 & 40 \\
\hline 28 & $\mathrm{P}$ & 400 & 3 & 12 & 0.47 & 1.5 & 37 \\
\hline 28 & $\mathrm{C}$ & 400 & 3 & 14 & 0.47 & 1.5 & 41 \\
\hline 29 & $\mathrm{P}$ & 400 & 3 & 11 & 0.47 & 1.5 & 37 \\
\hline 29 & $\mathrm{C}$ & 400 & 3 & 13 & 0.47 & 1.5 & 40 \\
\hline 30 & $\mathrm{P}$ & 400 & 3 & 11 & 0.40 & 1.5 & 35 \\
\hline 30 & $\mathrm{P}$ & 400 & 4 & 15 & 0.67 & 1.5 & 38 \\
\hline 30 & $\mathrm{C}$ & 400 & 3 & 11 & 0.40 & 1.5 & 39 \\
\hline 30 & $\mathrm{C}$ & 400 & 4 & 15 & 0.67 & 1.5 & 45 \\
\hline
\end{tabular}

Table 2 shows the set of lighting solutions obtained for rural instances using the minimum luminance $L_{\min }=1,5-1,6 \mathrm{~cd} / \mathrm{m}^{2}$. We can observe in Table 2 that at the same values both of uniformity ratio of illumination and of required power ratings, the perimetrical layout implies lower mounting heights of luminaries and shows values of illumination lesser than the central layout. Indeed, the height of a pole placed in the central island cannot be less than a minimal threshold in order to preserve the incoming drivers from unsafe dazzling effects. 


\section{Benefits}

The main value of any good intersection lighting is directly related to a reduction in the night time accident rate. Nevertheless, in order to make a comparison with costs, we can restrict the field of interest taking into account some aspects belonging to one of the following three categories.

First of all, the lighting performances are resumed by the values achieved for the average levels of luminance, average illumination and overall uniformity ratio of illumination.

Secondly, the geometric and visual impressions are related both to the rate of path discontinuity influencing vehicle trajectories and speeds, and to the extent of clearness of roadway space perception transmitted to the approaching drivers. Thirdly, a roundabout better lighting makes a major contribute to the enhancement of its surroundings, improving city activities and beautifying intersection points.

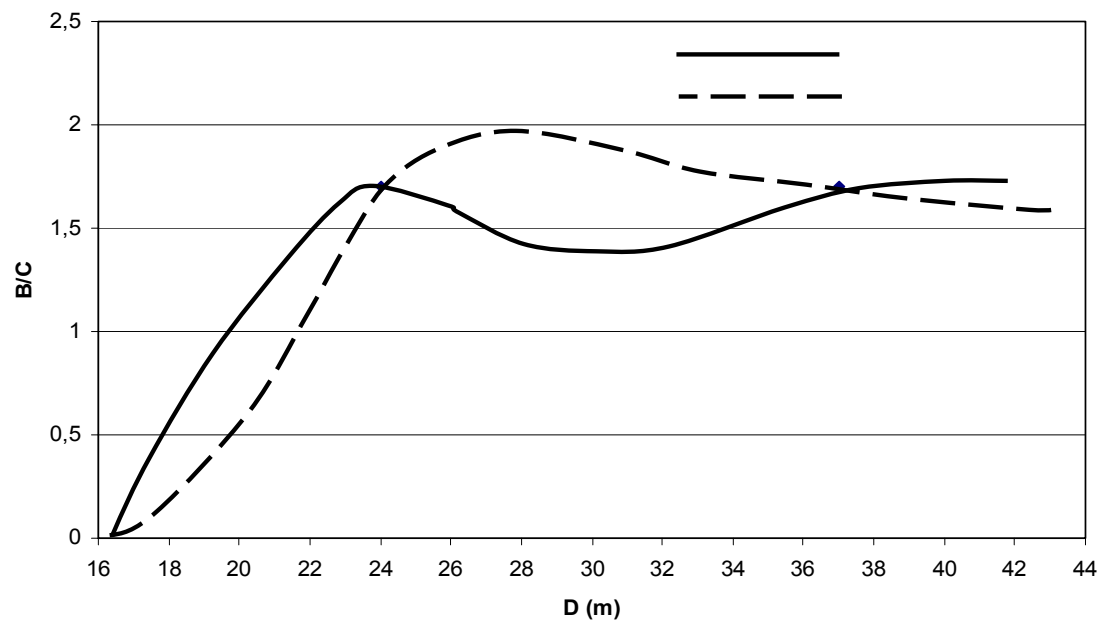

Figure 6: Linear cost model plotted for the two different layouts.

These benefits have been quantified and added through a multicriterial standard process [5]. The ratio of benefits to costs in respect to each $D$ of the roundabout leads to the two curves depicted in Figure 6. Such a result shows clearly that in the range from 24 to $37 \mathrm{~m}$ the central solution is preferable to the perimetrical one. It important to observe that such a range covers in practice the compact roundabout category. In other words, the optimal lighting plan for a compact roundabout is central layout based.

Over $37 \mathrm{~m}$ the perimetrical layout prevails because the central solution requires even higher mounting heights. This last fact implies rising costs required by the so-called high-mast lighting technique under the same extent of 
benefits. However, the designer is able to select the optimal layout for its related lighting plan entering in Figure 4 with a given value of $D$ of any compact roundabout.

\section{Conclusions}

This paper is based on empirical results leading to the conclusion that the central based layout is optimal for any compact roundabout lighting plan. Whereas any large roundabout, i.e. with an inscribed circle diameter over $40 \mathrm{~m}$, shows clearly that the perimetrical solution prevails over the central one.

The above conclusion found its own validity in respect to the assumptions posed during the computational process, obviously. Nevertheless, these assumptions are quite general and recurrent to be well-suited for many real world instances.

Finally, the paper shows two experimental diagrams and associated tables allowing the design of the most proper lighting plan for the given value of $25 \mathrm{~m}$ or $30 \mathrm{~m}$ of the inscribed diameter $D$, or vice versa.

\section{References}

[1] Pratelli A., Design of modern roundabouts in urban traffic systems in Brebbia and Dolezel (eds.), Urban Transport XII, WIT Press, Ashurst Lodge, pp. 83-93, 2006.

[2] CIE - Commission Internationale de l'Éclairage, Recommendations for the lighting of roads for motor and pedestrian traffic. Report n. 115/95, 1995.

[3] Norma UNI 10819, Luce ed Illuminazione - Impianti di illuminazione esterna - Requisiti per la limitazione della dispersione verso l'alto del flusso luminoso.

[4] CERTU - Centre d'Études sur les Réseaux, les Transports, l'Urbanisme et les Constructions Publiques, Guide Carrefours Urbains - Chapitre 9 : Les Giratoires, 1999.

[5] Scatena P., Studio dei sistemi di illuminazione delle rotatorie in funzione della sicurezza stradale. Tesi di Laurea a.a. 2003/04, Facoltà di Ingegneria, Università di Pisa (Italy).

[6] Rowan N.J. and Walton N.E., Lighting of traffic facilities in Homburger W. (ed.) Transportation and Traffic Engineering Handbook, PrenticeHall, pp. 627-644, 1982.

[7] Norme Swisse - SN 640263, Carrefours giratoires, VSS, Zurich 2000. 